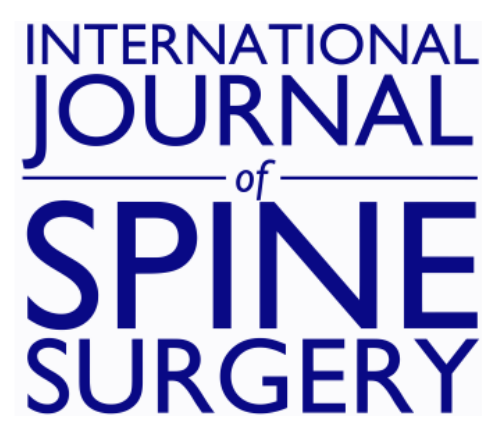

\title{
Pull-Out Strength Comparison Among Conventional Pedicle Screw, Cortical Infero-Superior, and Cortical Supero-Inferior Trajectories in Yorkshire Porcine Lumbar Spines: A Biomechanical Study
}

SINGKAT DOHAR A. L. TOBING and RIZKY P. WISNUBAROTO

Int J Spine Surg 2020, 14 (4) 580-584

doi: https://doi.org/10.14444/7077

http://ijssurgery.com/content/14/4/580

This information is current as of April 25, 2023.

Email Alerts Receive free email-alerts when new articles cite this article. Sign up at:

http://ijssurgery.com/alerts 


\title{
Pull-Out Strength Comparison Among Conventional Pedicle Screw, Cortical Infero-Superior, and Cortical Supero-Inferior Trajectories in Yorkshire Porcine Lumbar Spines: A Biomechanical Study
}

\author{
SINGKAT DOHAR A. L. TOBING, MD, RIZKY P. WISNUBAROTO, MD \\ Department of Orthopaedics and Traumatology, Cipto Mangunkusumo General Hospital, Jakarta, Indonesia
}

\begin{abstract}
Background: Posterior instrumentation of the spine presents a challenge, especially in conditions with low bone quality. Pedicle screw insertion with cortical bone trajectory is designed to add interface between the screw and the bone through engagement between pedicles and the cortex when compared to conventional screw course. Pedicle screw insertion trajectory from cortical infero-superior and the proposed cortical supero-inferior should obtain better pull-out performance than conventional pedicle trajectory. We aim to evaluate the pull-out strength differences among conventional pedicle screw, cortical infero-superior, and cortical supero-inferior trajectories.

Methods: Samples from Yorkshire porcine lumbar spine (L1-L5; $\mathrm{n}=30$ ) were relieved of soft tissue attachments and dried. Morphometric measurements were conducted, and the samples were randomly assigned to 3 groups. The screws were inserted into the vertebrae by drilling with the 3 trajectories: conventional, cortical infero-superior, and cortical supero-inferior. The trajectories of the screws were examined using x-rays. Pull-out tests were conducted by applying uniaxial traction in line with the screw trajectory with a translational speed of $5 \mathrm{~mm} / \mathrm{min}$. The results of the pull-out are measured in Newtons.

Results: We obtained a mean value of pull-out force in conventional trajectory of $491.72 \pm 187.2 \mathrm{~N}$, cortical infero-superior of $822.16 \pm 295.73 \mathrm{~N}$, and cortical supero-inferior of $644.14 \pm 201.97 \mathrm{~N}$. Cortical infero-superior and cortical supero-inferior trajectories attained $67 \%$ and $30 \%$ higher pull-out mean, respectively. Using 1-way analysis of variance and a post hoc Tukey test revealed a significant difference between cortical infero-superior and conventional trajectories $(P<.01)$. Differing pull-out strengths between cortical infero-superior and supero-inferior trajectories showed no statistical significance. Results of our study showed a $30 \%$ higher pull-out strength in our proposed trajectory than the conventional one, although not statistically significant.
\end{abstract}

Conclusions: The trajectory of the screws within the lumbar spine seemed to have an impact in pull-out strength. Cortical bone engagement using the novel trajectories may increase pull-out strength of pedicle screws.

Level of Evidence: Level 5.

Biomechanics

Keywords: pedicle screw trajectory, cortical bone trajectory, osteoporosis, biomechanics

\section{INTRODUCTION}

The increase in life expectancy of the general population will lead to an increase in problems of the spine due to aging or degeneration process. In 2010 , the number of people over the age of 65 was 524 million, with the number increasing to 1.5 billion in 2015 , or $16 \%$ of the world's population. ${ }^{1}$

Problems arising from the spine may be due to the degenerative process of bone quality or deterioration of spinal disc and facet joints. Some of these problems may need posterior instrumentation of the spine. ${ }^{2-4}$
Posterior instrumentation is aimed at achieving spinal fusion, which is helped by maintaining stable screw insertion within the pedicle. However, posterior instrumentation in porotic pedicle lumbal spine may cause loosening and failure of fixation. Pedicle screw insertion with cortical bone trajectory (CBT) is designed to add interface between the screw and the bone through engagement between pedicles and the cortex when compared to conventional pedicle screw insertion. Pedicle screw insertion from cortical inferosuperior and the proposed cortical supero-inferior trajectories should obtain better pull-out performance 


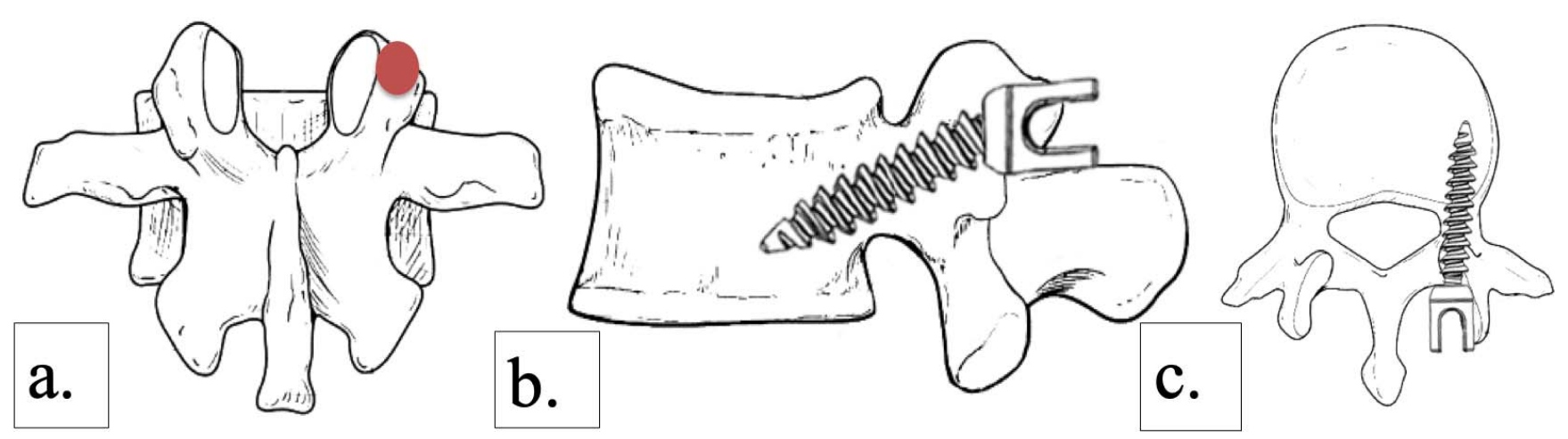

Figure 1. Trajectory proposed by the authors. (a) The screw insertional point. (b) Sagittal view of the screw after insertion for superior to inferior. (c) An axial cut of the screw trajectory to slightly lateral.

than conventional pedicle trajectory. We aim to evaluate the pull-out strength differences among conventional pedicle screw, CBT infero-superior, and proposed CBT supero-inferior trajectories. ${ }^{5-8}$

\section{METHODS}

For our experimental study, we obtained 6 female Yorkshire pigs. The age of the pigs were between 6 and 8 months; all were healthy with no deformities. We separated lumbar vertebrae 1-5. Then we fixated the specimens in formaldehyde $10 \%$ for 2 weeks. We then removed the surrounding tissue from the lumbar spine and dried our samples in a dry box with $30 \%$ humidity at $26^{\circ} \mathrm{C}$ for 3 weeks until only the bone remained. We measured the vertebral body height, body diameter, superior pedicle diameter, pedicle anterior corpus width, and spinal canal width by using a digital caliper (Mitutoyo 500-182-30; Mitutoyo, Kawasaki, Japan).

We then randomly assigned 10 lumbar vertebrae into 3 groups (conventional, cortical supero-inferi- or, and cortical infero-superior trajectories) and performed pedicle screw insertions using the methods described by Weinstein et $\mathrm{al}^{8}$ for our conventional trajectory, Santoni et $\mathrm{al}^{6}$ for the cortical infero-superior trajectory and our proposed trajectory (Figure 1). Insertional holes were made using an awl. We then prepared the trajectory using a Lenke probe and a $3-\mathrm{mm}$ diameter drill bit with a power tool.

We used traditional polyaxial screws (length 35 $\mathrm{mm}$ and outer diameter of $4.5 \mathrm{~mm}$; Changzhou Waston Medical Appliance Co, Changzhou, China) that complied with the standards of GB/T13810 and ISO5832-3: 1996. After screw insertion, we confirmed their positions using a radiograph and to ensure correct trajectories of the screws.

Screw pull-out testing was performed using a universal testing machine (Gotech AI-7000S; Gotech, Taichung, Taiwan). We positioned our samples on a platform that we designed to ensure an axial placement between the screw and the testing machine. The screws were then connected to an insertion screwdriver and pulled out at a speed of 5

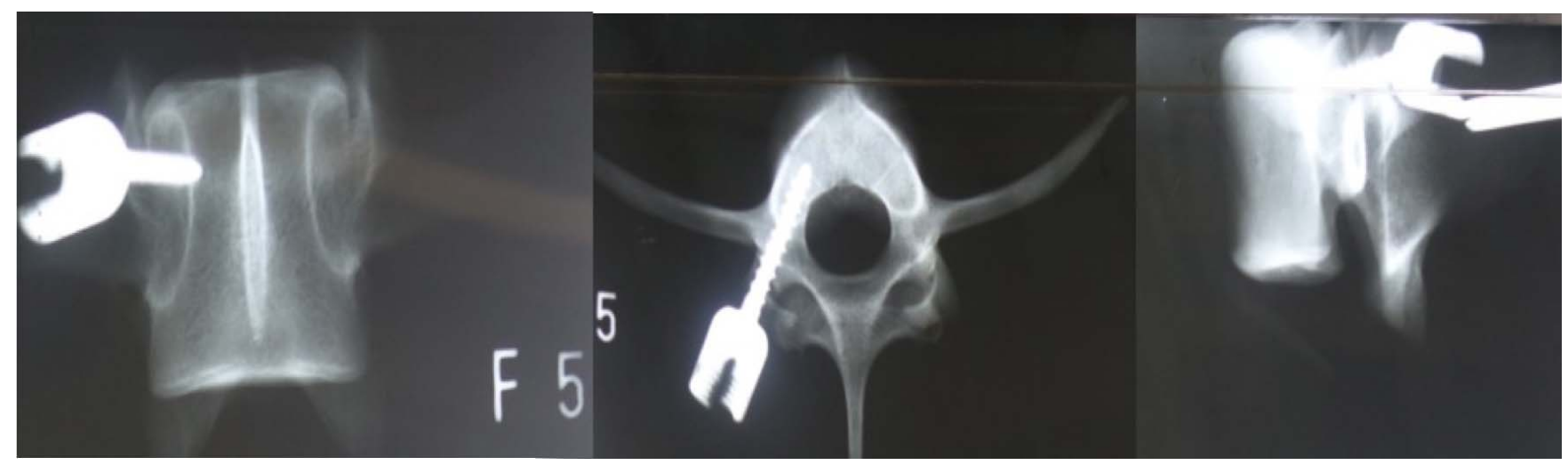

Figure 2. Pedicle screw insertion with conventional trajectory. 


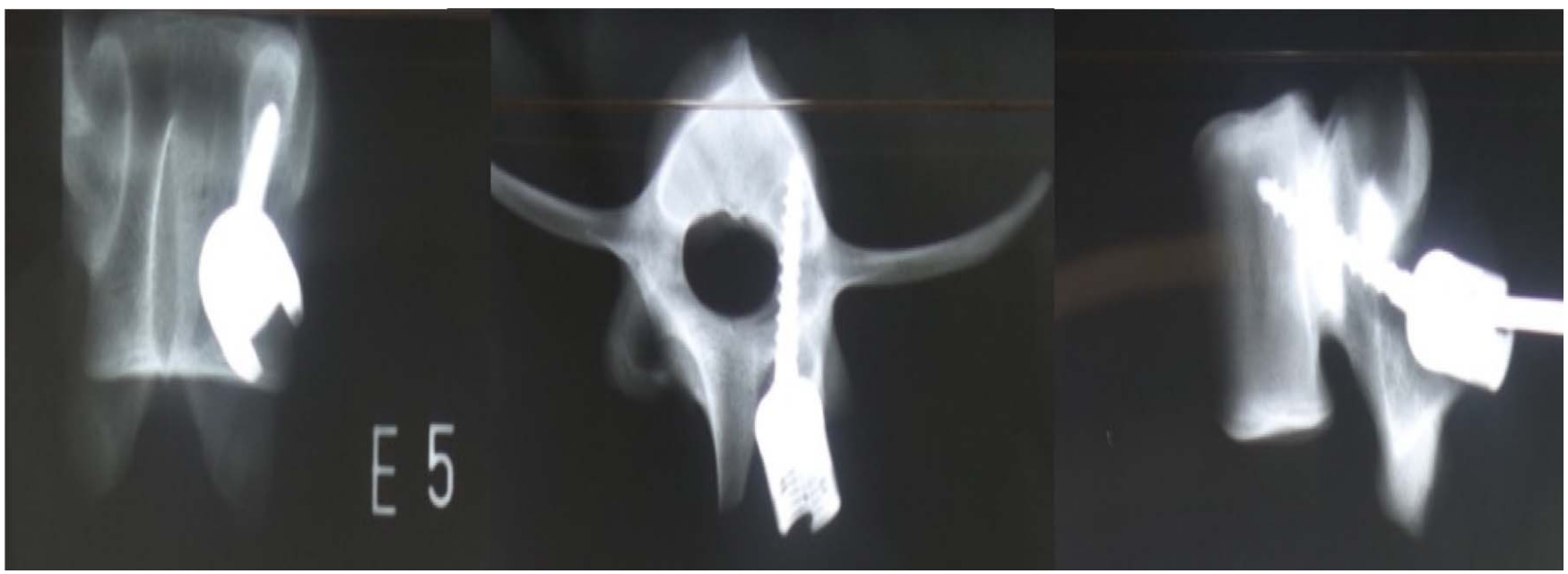

Figure 3. Pedicle screw insertion with cortical bone infero-superior trajectory.

$\mathrm{mm} / \mathrm{min}$. The point of deflection in the force profile was noted as the pull-out strength of the screws (Figures 2-5).

We recorded the results and performed statistical analysis using SPSS Statistics version 25 (SPSS Inc, Chicago, IL). The means of the pull-out value were analyzed using 1-way analysis of variance (ANOVA). The $P$ value $<.05$ was considered statistically significant.

\section{RESULTS AND DISCUSSION}

The measurements of the porcine lumbar vertebrae were comparable with the studies performed by Dath et $\mathrm{al}^{9}$ and Busscher et $\mathrm{al}^{11} \mathrm{We}$ found no discernable morphologic differences between of the trajectory groups (Table). The porcine lumbar pedicle height and width were comparable to humans. $^{9-11}$

The mean resistance of pull-out strength for the conventional trajectory was $491.72 \pm 187.2 \mathrm{~N}$, CBT infero-superior 822.16 $\pm 295.73 \mathrm{~N}$, and CBT supero-inferior $644.14 \pm 201.97 \mathrm{~N}$ (Figure 6). The pull-out values of the screws were normally distributed. One-way ANOVA test showed a statistically significant difference between groups. The post hoc Tukey test showed significance only between the conventional and infero-superior trajectory groups. ${ }^{6}$

Different screw trajectory will lead to difference in pull-out strength. Santoni et $\mathrm{al}^{6}$ in 2009 showed a $30 \%$ increase in pull-out strength with screws with CBT compared with conventional trajectory. Ueno

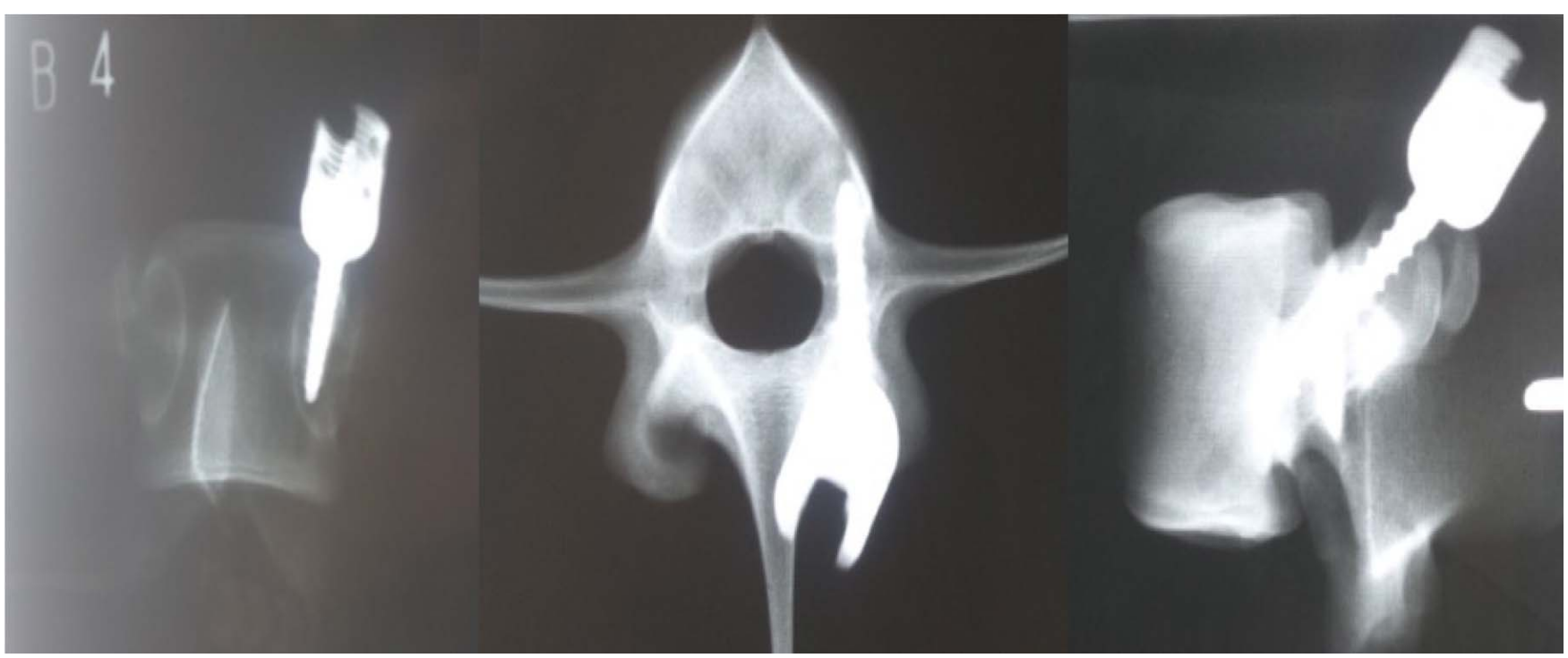

Figure 4. Pedicle screw insertion with cortical bone supero-inferior trajectory. 


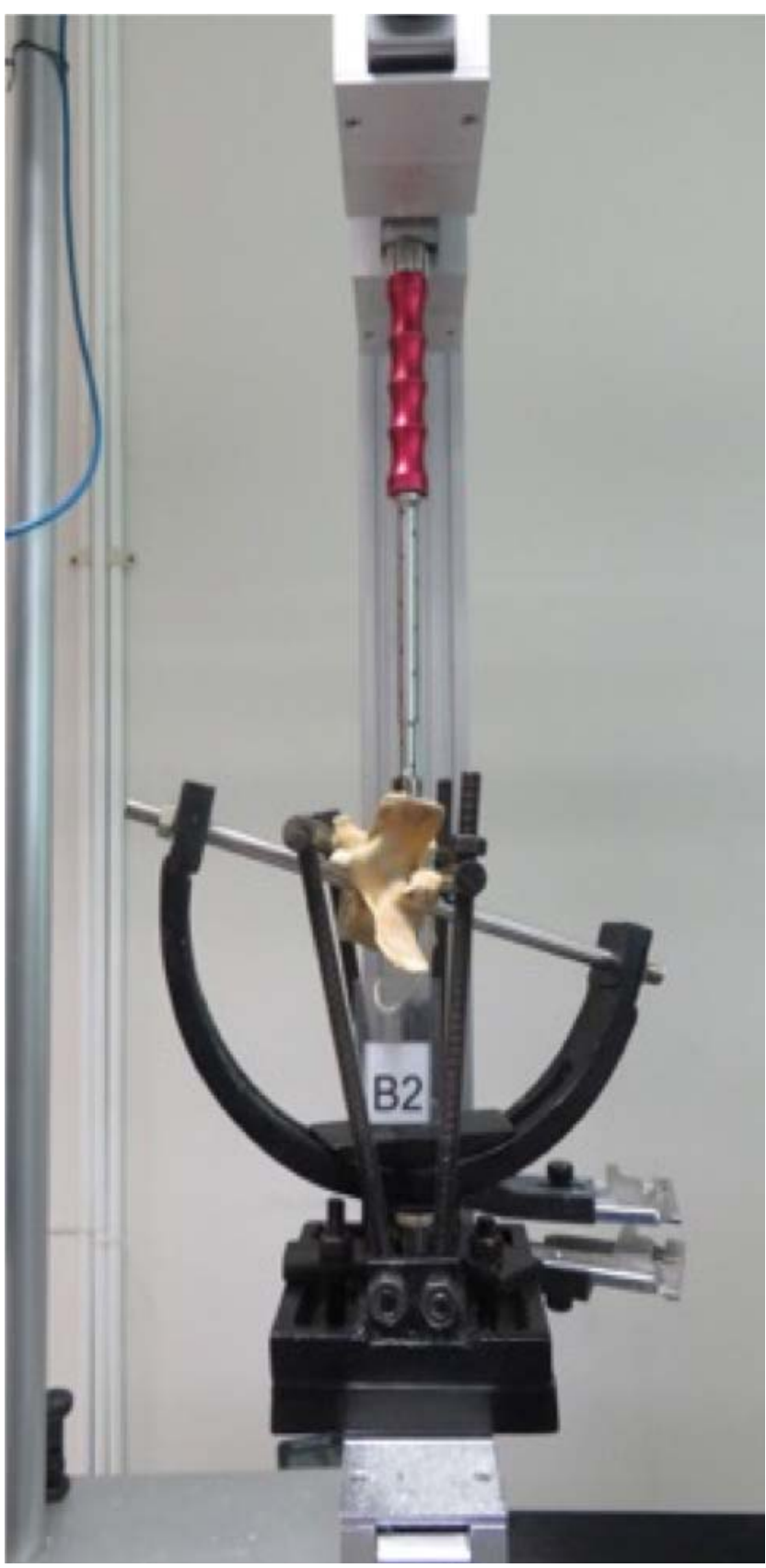

Figure 5. Pull-out testing. The screw is connected to the insertion screwdriver in the apparatus that was designed to hold the vertebrae and the screw in line with the machine. The screw was then pulled out in the direction of the insertion.

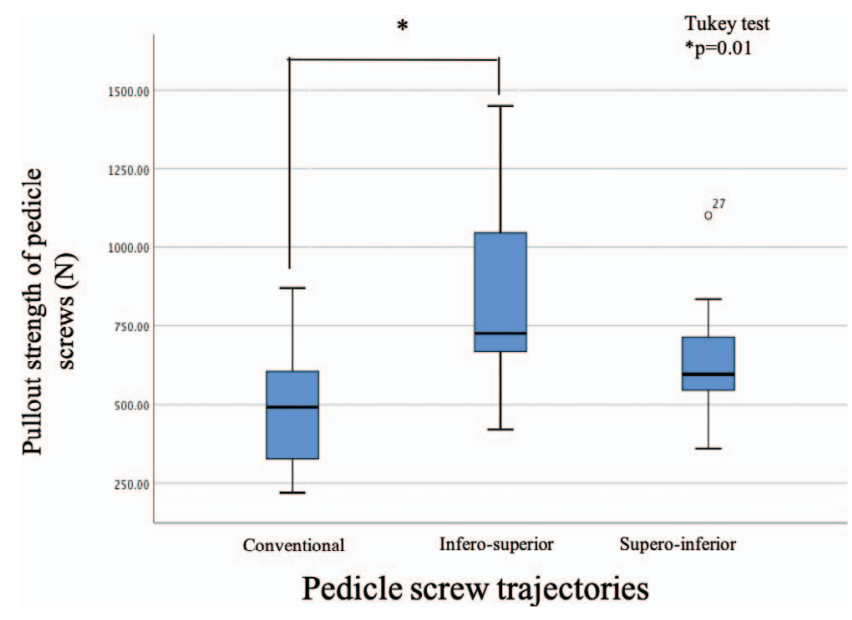

Figure 6. Maximum pull-out strength of the screws during pull-out testing. Pullout strength was greater in the cortical bone infero-superior group. A statistically significant result was found only between the conventional and cortical bone infero-superior groups. Error bars indicate significant differences.

et $\mathrm{al}^{12}$ produced similar results: a $29.5 \%$ increase in pull-out strength compared with conventional screws. Matsukawa et $\mathrm{al}^{13}$ showed that controlling bone mineral denisty and screw type yields different pull-out strengths. Our results showed a $67 \%$ increase in the trajectory of Santoni et $\mathrm{al}^{6}$ and $30 \%$ increase in pull-out strength from our proposed trajectory compared with the conventional trajectory. $6,12,13$

Decreasing bone quality leads to decrease in screw-bone interface. The infero-superior trajectory start point may engage the inferior lamina cortex first, "force nucleus" (confluence area at the transverse process, lamina, facet inferior, and superior pedicle). To catch more cancellous bone and to engage the cortical area, the supero-inferior trajectory engages the inferior end plate, which is a denser area of the lumbar spine compared with the superior end plate. ${ }^{13,14}$

Pull-out strength is still considered an effective method of measuring screw strength within a bone. Pull-out test methodology differs between investigators, especially in the manner of fixation of the

Table. Sample characteristics.

\begin{tabular}{lccr}
\hline & $\begin{array}{c}\text { Conventional Trajectory, } \\
\text { Mean (SD), } \mathbf{n}=\mathbf{1 0}\end{array}$ & $\begin{array}{c}\text { Cortical Bone } \\
\text { Infero-Superior Trajectory, } \\
\text { Mean (SD), } \mathbf{n}=\mathbf{1 0}\end{array}$ & $\begin{array}{c}\text { Cortical Bone } \\
\text { Supero-Inferior Trajectory, } \\
\text { Mean (SD), } \mathbf{n}=\mathbf{1 0}\end{array}$ \\
\hline Vertebral body height (mm) & $32.8(2.48)$ & $32.8(2.69)$ & $33.1(1.66)$ \\
Vertebral body diameter (mm) & $20.5(1.5)$ & $20.2(1.1)$ & $20.2(1.22)$ \\
Canal width (mm) & $16.7(3.23)$ & $16.1(3.1)$ & $17.2(1.87)$ \\
Right pedicle width (mm) & $8.9(2.13)$ & $8.3(1.7)$ & $9.2(1.40)$ \\
Left pedicle width (mm) & $8.95(2.07)$ & $8.26(1.68)$ & $9.1(1.33)$ \\
Right pedicle height (mm) & $11.3(0.95)$ & $11.30(0.95)$ & $11.1(1.45)$ \\
Left pedicle height (mm) & $11.26(1.0)$ & $11.21(0.65)$ & $11.04(1.16)$ \\
\hline
\end{tabular}


specimen to the measuring device. Some prefer fixation using embedded resin; others prefer mechanical fixture. No authors have showed superiority over these differing fixation methods. ${ }^{15}$

\section{CONCLUSIONS}

There is a difference between pull-out strengths in pedicle screws with different trajectories; the highest pull-out strength was obtained with the cortical infero-superior group, the lowest with the conventional trajectory. We found a statistically significant difference between pull-out strength of the conventional trajectory and the cortical infero-superior group. No statistical difference of pull-out strength was noted between our proposed trajectory, the conventional trajectory, and the cortical inferosuperior group. This study may be used as a baseline for further studies using human cadaveric studies and other biomechanical outcomes.

\section{ACKNOWLEDGMENTS}

The authors would like to thank all the staff of Department of Orthopaedics and Traumatology at the Faculty of Medicine University of Indonesia for the suggestions and corrections in writing this article. We would like to express our gratitude to all contributors.

\section{REFERENCES}

1. Mithal A, Bansal B, Kyer CS, Ebeling P. The Asia-Pacific Regional Audit - epidemiology, costs, and burden of osteoporosis in India 2013: a report of International Osteoporosis Foundation. Indian J Endocrinol Metab. 2014;18(4):449-454.

2. Szpalski M, Gunzburg R. Lumbar spinal stenosis in the elderly: an overview. Eur Spine J. 2003;12(Suppl 2):S170-175.

3. Otani K, Kikuchi S, Yabuki S, et al. Lumbar spinal stenosis has a negative impact on quality of life compared with other comorbidities: an epidemiological cross-sectional study of 1862 community-dwelling individuals. ScientificWorldJournal. 2013;2013:590652.

4. Cooper C, Atkinson EJ, Jacobsen SJ, O'Fallon WM, Melton LJ 3rd. Population-based study of survival after osteoporotic fractures. Am J Epidemiol. 1993;137(9):1001-1005.

5. Halvorson TL, Kelley LA, Thomas KA, Whitecloud TS 3rd, Cook SD. Effects of bone mineral density on pedicle screw fixation. Spine J. 1994;19(21):2415-2420.

6. Santoni BG, Hynes RA, McGilvray KC, et al. Cortical bone trajectory for lumbar pedicle screws. Spine J. 2009;9(5):366-373.

7. Wittenberg RH, Lee KS, Shea M, White AA 3rd, Hayes WC. Effect of screw diameter, insertion technique, and bone cement augmentation of pedicular screw fixation strength. Clin Orthop Relat Res. 1993;(296):278-287.

8. Weinstein JN, Rydevik BL, Rauschning W. Anatomic and technical considerations of pedicle screw fixation. Clin Orthop Relat Res. 1992;(284):34-46.

9. Dath R, Ebinesan AD, Porter KM, Miles AW. Anatomical measurements of porcine lumbar vertebrae. Clin Biomech (Bristol, Avon). 2007;22(5):607-613. http://www.ncbi. nlm.nih.gov/pubmed/17360085.

10. Kettler A, Schmoelz W, Shezifi Y, et al. Biomechanical performance of the new BeadEx implant in the treatment of osteoporotic vertebral body compression fractures: Restoration and maintenance of height and stability. Clin Biomech. 2006;21(7):676-682.

11. Busscher I, Ploegmakers JJ, Verkerke GJ, Veldhuizen AG. Comparative anatomical dimensions of the complete human and porcine spine. Eur Spine J. 2010;19(7):1104-1114. http://www.ncbi.nlm.nih.gov/pubmed/20186441.

12. Ueno M, Sakai R, Tanaka K, et al. Should we use cortical bone screws for cortical bone trajectory? J Neurosurg Spine. 2015;22(4):416-421. http://thejns.org/doi/10.3171/2014. 9.SPINE1484.

13. Matsukawa K, Yato Y, Imabayashi H, Hosogane N, Asazuma T, Chiba K. Biomechanical evaluation of lumbar pedicle screws in spondylolytic vertebrae: comparison of fixation strength between the traditional trajectory and a cortical bone trajectory. J Neurosurg Spine. 2016;24(6):910915. http://www.ncbi.nlm.nih.gov/pubmed/26895531.

14. Steffee AD, Biscup RS, Sitkowski DJ. Segmental spine plates with pedicle screw fixation. A new internal fixation device for disorders of the lumbar and thoracolumbar spine. Clin Orthop Relat Res. 1986;(203):45-53.

15. Yone K, Sakou T, Kawauchi Y, Yamaguchi M, Yanase M. Indication of fusion for lumbar spinal stenosis in elderly patients and its significance. Spine (Phila Pa 1976). 1996;21(2):242-248.

Disclosures and COI: The authors have no conflicts of interest to disclose. Ethical clearance was obtained from the Ethical Review Board of the Faculty of Medicine, University of Indonesia.

Corresponding Author: Rizky P. Wisnubaroto, MD, Department of Orthopaedics and Traumatology, Cipto Mangunkusumo General Hospital, Central Jakarta, Jakarta, Indonesia, 10430. Phone: (+62) $811 \quad 1068$ 10; Email: rizky.wisnubaroto@ gmail.com.

Published 28 August 2020

This manuscript is generously published free of charge by ISASS, the International Society for the Advancement of Spine Surgery. Copyright (c) 2020 ISASS. To see more or order reprints or permissions, see http://ijssurgery.com. 